\title{
Simulation of Quasi Cascaded H-Bridge Five-Level Boost Inverter
}

\author{
M.Devika ${ }^{1}$, M.Sundaraperumal ${ }^{2}$, M.Valan Rajkumar ${ }^{3}$ \\ ${ }^{1}$ Post-Graduate Scholar, Department of Electrical and Electronics Engineering, \\ Gnanamani College of Technology, Namakkal, Tamilnadu, India \\ ${ }^{2}$ Assistant Professor, Department of Electrical and Electronics Engineering, \\ Gnanamani College of Engineering, Namakkal, Tamilnadu, India \\ ${ }^{3}$ Professor, Department of Electrical and Electronics Engineering, \\ Gnanamani College of Technology, Namakkal, Tamilnadu, India
}

\begin{abstract}
:
Multilevel inverters have become more attractive for researchers due to low total harmonic distortion in the output voltage and low electromagnetic interference. This paper proposes a novel single-stage quasicascaded H-bridge five-level boost inverter. The proposed quasi cascaded h-bridge five-level boost inverter has the advantages over the cascaded $\mathrm{H}$-bridge quasi-Z-source inverter in cutting down passive components. Consequently, size, cost, and weight of the proposed inverter are reduced. A capacitor with low voltage rating is added to the proposed topology to remove an offset voltage of the output AC voltage when the input voltages of two modules are unbalanced. Besides, sinusoidal pulse width modulation techniques used here. PID controller is used to control the capacitor voltage of each module. This paper presents circuit analysis, the operating principles, and simulation results of the proposed system.
\end{abstract}

Keywords: z-source inverter, five level inverter, sinusoidal pulse width modulation, boost inverter, PID controller, Module.

\section{Introduction}

Multilevel inverters have recently received many attentions from researchers due to their advantages over the conventional three-level pulse-width modulation inverters. The advantages of the multilevel inverters are as follows: improved quality output waveforms with lower total harmonic distortion (THD),[1]-[10], smaller filter size and lower electromagnetic interface (EMI).

Three general multi level inverter topologies are: flying capacitors, neutral point clamped (NPC), and cascaded H-bridge (CHB) inverters. Among these topologies[12]-[15], the $\mathrm{CHB}$ inverter has unique advantages in modularity and its contribution of high power. These advantages make the CHB inverter an attractive option for many applications such as uninterruptible power supplies UPS), grid-connected system, Stat Com system, motor drive, etc. However, the traditional CHB multilevel inverter is a buck DC-AC power conversion,[22]-[25] where the converter is demanded for each module in the CHB topology to achieve the high AC output voltage when the DC input voltages are low. Adding
DC-DC boost power converter results in low efficiency and high cost[26]-[30].

The conventional two-stage CHB boost-five-level inverter has two capacitors two boost inductors, two diodes, ten switches, one filter inductor and a resistive load are utilized in the conventional CHBBFLI. The boost DC-DC converter is used to control the DC-link voltage on each $\mathrm{H}$-bridge circuit[5][40]. Both the top and bottom switches in the same leg cannot be switched on simultaneously because the DC-link capacitor is connected to each leg in parallel. And a dead-time between two switches in the leg must be used to avoid short circuit in the DC source

\section{Conventional CHB five-level inverters}

The traditional CHB multilevel inverters a buck DCAC power conversion, where the peak AC output voltage is limited by the total DC source voltages. An additional DC-DC boost converter is demanded for each module in the CHB topology to achieve the high AC output voltage when the DC input voltages are low. Adding DC-DC boost power converter results in low efficiency and high cost. 
The conventional two-stage CHB boost-five-level inverter (CHB-BFLI) has Two capacitors, two boost inductors, two diodes, ten switches, one filter inductor and a resistive load are utilized in the conventional CHB-BFLI. The boost DC-DC converter is used to control the DC-link voltage on each H-bridge circuit.

Both the top and bottom switches in the same leg cannot be switched on simultaneously because the DC-link capacitor is connected to each leg in parallel. And a dead-time between two switches in the leg must be used to avoid short circuit in the DC source.

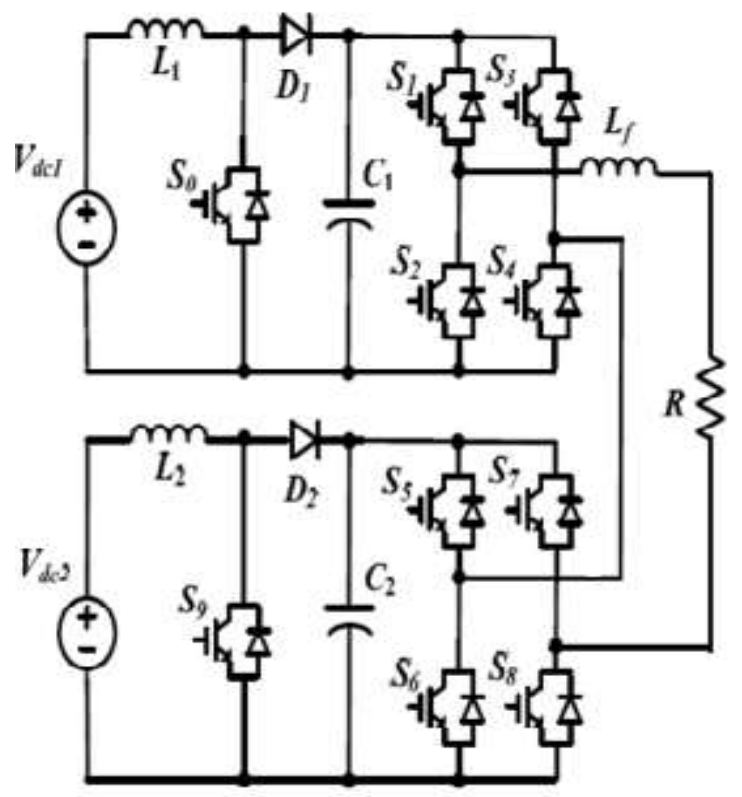

Figure 2.1 Conventional CHB five-level inverters

In the conventional CHB-BFLI, the boost DC-DC converter is used to control the DC-link voltage on each H-bridge circuit. As shown in Fig.(a), both the top and bottom switches in the same leg cannot be switched on simultaneously because the DC-link capacitor is connected to each leg in parallel. And a dead-time between two switches in the leg must be used to avoid short circuit in the DC source.

\section{QCHB-FLBI topology}

In this paper, AQZS modular cascaded converter is addressed in for dc integration of high-power PV system. Energy stored CHB-QZSI based PV power generation system is proposed. Fault-tolerant $\mathrm{CHB}$ inverters using $\mathrm{Z}$-sourced network are investigated. A cascaded transformer-based multilevel inverter using single Z-source network is presented. An active-front-end (AFE) CHB multilevel inverter based on dual-boost/buck converter is proposed.

Like the CHB-QZSI, the AFE-CHB inverter also has the shoot-through immunity and buck/boost voltage. However, the CHB-QZSI in and the AFE-CHB inverter use a large number of passive elements with raising the size, cost, and weight of the power cascaded system.

A quasi-switched boost (QSB) network is used to replace the QZS network. In comparison to the QZS network, the QSB network uses one less capacitor, one less inductor, one more diode and one more switch in front of the main $\mathrm{H}$-bridge circuit. An isolated high step-up DC-DC converter is proposed in based on the QSB network. In this paper, a new single-stage quasi-cascaded H-bridge five-level boost inverter (QCHB-FLBI) is proposed. In the proposed QCHB-FLBI, the QSB network as presented is used in each module.

The main features of the proposed QCHB-FLBI are five-level output voltage with boost voltage ability, reduction in a number of passive components and shoot-through immunity. The proposed inverter consists of two separate DC sources, two quasiboost inverter (QBI) modules and an inductor filter connected to the resistive load in series. Each QBI module contains one capacitor, one boost inductor, four switches and two diodes. The output voltage of the proposed QCHB-FLBI has five levels.

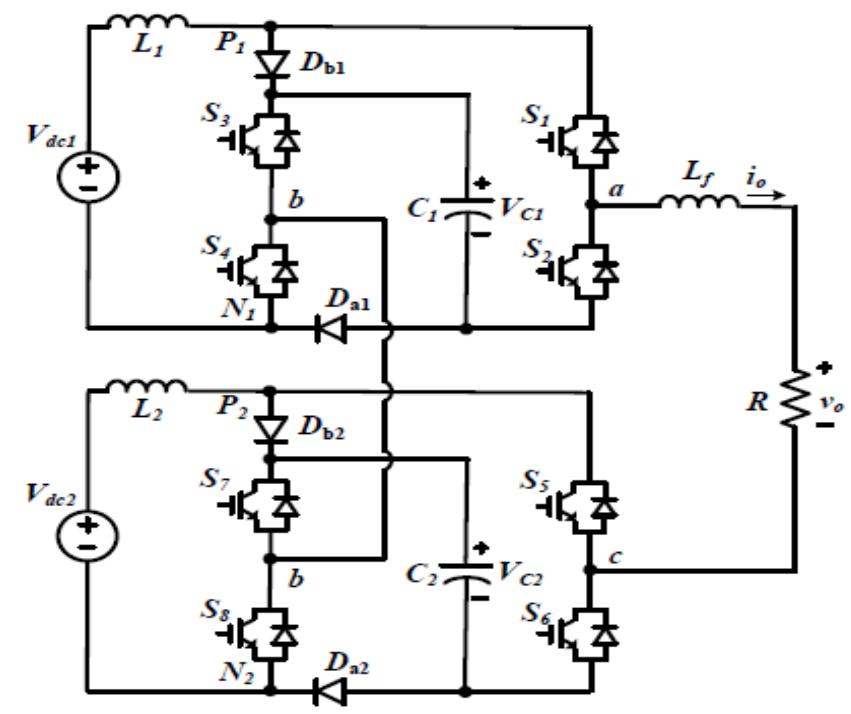

Figure 3.1 Proposed QCHB-FLBI topology

Single-stage quasi-cascaded H-bridge five-level boost inverter (QCHB-FLBI) is proposed. The proposed inverter consists of two separate DC 
sources, two quasi-boost inverter (QBI) modules and an inductor filter connected to the resistive load in series. Each QBI module contains one capacitor, one boost inductor, four switches and two diodes. The output voltage of the proposed QCHB-FLBI has five levels. In the CHB-QZSI, the operating frequency of the inductors is to fold the switching frequency.

Therefore, the high-frequency current ripple on inductors of the proposed QCHB-FLBI is a half that of the CHB-QZSI. Capacitor voltages of the proposed inverter are higher than those of the CHBQZSI .However, total capacitor voltage stresses in each module of both inverters are the same. The voltage stress on diodes and switches of the proposed inverter equals to that of the CHB-QZSI.

\section{Operation of Proposed Sysytem}

Multilevel inverters have recently received many attentions from researchers due to their advantages over the conventional three-level pulse-width modulation (PWM) inverters. The advantages of the multilevel inverters are as follows: improved quality output waveforms with lower total harmonic distortion (THD), smaller filter size and lower electromagnetic interface (EMI). Three general multilevel inverter topologies are: flying capacitors, neutral point clamped (NPC), and cascaded H-bridge (CHB) inverters.

Among the set topologies, the CHB inverter has unique advantages in modularity and its contribution of high power. These advantages make the CHB inverter an attractive option for many applications such as uninterruptible power supplies A CHB quasi-Z-source inverter (QZSI) with single-stage power conversion was proposed .

The CHB five-level QZS network with two capacitors and two inductors is connected to each $\mathrm{H}$ bridge circuit. In the CHB-QZSI, a shoot-through (ST) state is used to boost voltage without any damages in the power circuit. In one switching period, the number of the ST states in the singlephase QSBI is two. Therefore, the operating frequency of the inductors is twofold the switching frequency. In the CHB-QZSI, the input DC current is continuous with low ripple. Each module in the CHB QZSI can produce the same DC-link voltage by control the ST duty cycle.

An effective control method, including system-level control and PWM for single-phase CHB-QZSI based grid-tie photovoltaic (PV) power system. Three- phase CHB-QZSI's control is proposed and demonstrated for application to PV power systems. A QZS modular cascaded converter is addressed for dc integration of high-power PV systems. Energy stored CHB-QZSI based PV power generation system is proposed. Fault-tolerant CHB inverters using Z-sourced network are investigated.

A cascaded transformer-based multilevel inverter uses a single Z-source network. An active-front-end (AFE) CHB multilevel inverter based on dualboost/buck converter is proposed. Like the CHBQZSI, the AFE-CHB inverter also has the shootthrough immunity and buck/boost voltage.

\section{Module Operation}

Phase-shifted sinusoidal pulse-width modulation (PS-SPWM) strategy for the proposed QCHB-FLBI, For module 1, two control voltages, are compared to a high-frequency triangle voltage to produce control signals for the $S 1$ and $S 2$ switches.

Two DC Voltage, are compared to produce the S0acontrol signal. Then $\mathrm{SOa}$ is added to the control signals of switches $\mathrm{S} 1$ and $\mathrm{S} 2$ to produce the ST states. Likewise, the voltage control is shifted in $90^{\circ}$ to create another high-frequency triangle voltage, produce control signals for the S3 and S4switches. Voltages are compared to produce aSOb control signal. The SObis then added to the control signals of switches $S 3$ and $S 4$ to produce the ST states.

As a result, the output voltage $\mathrm{v}$ of $\mathrm{H}$-bridge module 1 has three levels. Similar for the second H-bridge module, two control voltages are shifted in $180^{\circ}$ to produce the output voltage $\mathrm{vcb}$ of the $\mathrm{H}$-bridge module 2.

The output voltage vac of the cascaded system is a subtraction of $v a b$ and $v c b$.Therefore, the output voltage of the proposed QCHB-FLBI produces Fivelevel cascaded H-Bridge Quasi Z-Source Inverter with Quasi Impedance Network to each DC link of the PV module.

The impedance network consists of two inductors L1, L2 and two Capacitors C1 and C2 at each stage of the inverter bridge. This unique LC network connected to the inverter bridge modifies the operation of the circuit, allowing the shoot-through states and will effectively protect the circuit from damage when the short circuit occurs. By effectively utilizing the shoot-though state, the QZS network boosts the dc-link voltage. The major advantages of 
QZSI compared to other Z-inverters are .It draws a continuous constant dc current from the source.

The voltage on capacitor $\mathrm{C} 2$ is greatly reduced. The continuous and constant dc current drawn from the source make this topology well suited for PV power conditioning systems.

The proposed inverter consists of two separate DC sources, two quasi-boost inverter (qBI) modules and an inductor filter connected to the resistive load in series. Each qBI module contains one capacitor, one boost inductor, four switches and two diodes. The output voltage of the proposed qCHB-FLBI has five levels. Assuming that two qBI modules have the same parameters, the qBI module 1 in the proposed system is used to analyze the operating principle. Fig. 3 shows the operating modes of the qBI module 1 in the proposed inverter. In the shoot-through (ST) state 1, as shown in Fig. 3(a), both $\mathrm{S} 1$ and $\mathrm{S} 2$ are turned on. Da1 is conducting, while Db1 is blocking. If $\mathrm{S} 3$ is turned on, the output voltage of the qBI module 1 is - VC1. Else, it equals zero. The inductor L1 is charged from the Source. we have

$L_{1} \frac{d i_{L_{1}}}{d t}=V_{d c l}$.

In the ST state 2, S3 and $S 4$ are turned on as shown in Fig. 3(b). Dal is blocking, while $D b l$ is conducting. If $S 2$ are turned on, the output voltage of the qBI module 1 is $-V C 1$. Else, it equals zero. The inductor $L 1$ is also charged in this state, and its voltage is calculated as (1). In the non-shoot-through (NST) state 1, as shown in Fig. 3(c), both $S 1$ and $S 3$ are turned on. In the NST state 4, as shown in Fig. 3(f), both $S 2$ and $S 4$ are turned on. The output voltage of the qBI module 1 in both NST states 1 and 4 is zero. In the NST state 2, as shown in Fig. 3(d), both $S 2$ and $S 3$ are

Turned on. The output voltage of the qBI module 1 is $-V C 1$. In the NST state 3, as shown in Fig. 3(e), both $S 1$ and $S 4$ are turned on. The output voltage of the qBI module 1 is $V C 1$. During the non-shootthrough (NST) states as shown in Figs. 3(c)-3(f), $D a l$ and $D b l$ are conducting. The capacitor $C l$ is charged from $V d c$, while the inductor $L 1$ transfers energy from the DC voltage source to the main circuit. The $\mathrm{H}$-bridge circuit is equivalent as a current source, $i P N 1$. We get:

$$
L_{1} \frac{d i_{L_{1}}}{d t}=V_{d e l}-V_{C l}
$$

In one switching period, $T$, each leg has twice short circuits alternatively. From (1) and (2), the average inductor voltage

$\bar{V}_{L l}=\left(1-2 \frac{T_{0}}{T}\right)\left(V_{d c l}-V_{C l}\right)+2 \frac{T_{0}}{T} V_{d c l}$,

Where $T O / T=D 1$ is a ST duty ratio in each leg of module $1 ; T 0$ is total ST time intervals in one leg.

In a steady state, the average inductor voltage should be zero. We get:

$V_{\mathrm{Cl}}=\frac{1}{1-2 I_{0} / T} V_{d \mathrm{l} 1}=\frac{1}{1-2 D_{1}} V_{d \mathrm{l}}$

Similarly, we also obtain the capacitor voltage on the module 2 as

$V_{C 2}=\frac{1}{1-2 D_{2}} V_{\text {dc2 }}$

\section{Advantages of Proposed System}

High-frequency current ripple is less

Increase the efficiency

Reduced number of components

Reduce in cost

\section{Simulation Theory}

\section{General}

MATLAB (matrix laboratory) is a numerical computing environment and fourth-generation programming language. Developed by Math Works, MATLAB allows matrix manipulations, plotting of functions and data, implementation of algorithms, creation of user interfaces, and interfacing with programs written in other languages, including $\mathrm{C}$, $\mathrm{C}++$, Java, and FORTRAN. Although MATLAB is intended primarily for numerical computing, an optional toolbox uses the Mu PAD symbolic engine, allowing access to symbolic computing capabilities. An additional package, adds graphical multi-domain simulation and Model-Based Design for dynamic and embedded systems.

In 2004, MATLAB had around one million users across industry and academia. MATLAB users come from various backgrounds of engineering, science, and economics. MATLAB is widely used in academic and research institutions as well as industrial enterprises.

\section{Simulink}

Simulink, developed by Math Works, is a commercial tool for modeling, simulating and analyzing multi-domain dynamic systems. Its 
primary interface is a graphical block diagramming tool and a customizable set of block libraries. It offers tight integration with the rest of the MATLAB environment and can either drive MATLAB or be scripted from it. Simulink is widely used in control theory and digital signal processing for multidomain simulation and Model-Based Design Simulink is a block diagram environment for multidomain simulation and Model-Based Design. It supports system-level design, simulation, automatic code generation, and continuous test and verification of embedded systems. Simulink provides a graphical editor, customizable block libraries, and solvers for modeling and simulating dynamic systems. It is integrated with MATLAB, enabling you to incorporate MATLAB algorithms into models and export simulation results to MATLAB for further analysis.

\section{Building The Model}

Simulink provides a set of predefined blocks that you can combine to create a detailed block diagram of your system. Tools for hierarchical modeling, data management, and subsystem customization enable you to represent even the most complex system concisely and accurately.

\section{Proposed Simulation Circuit}

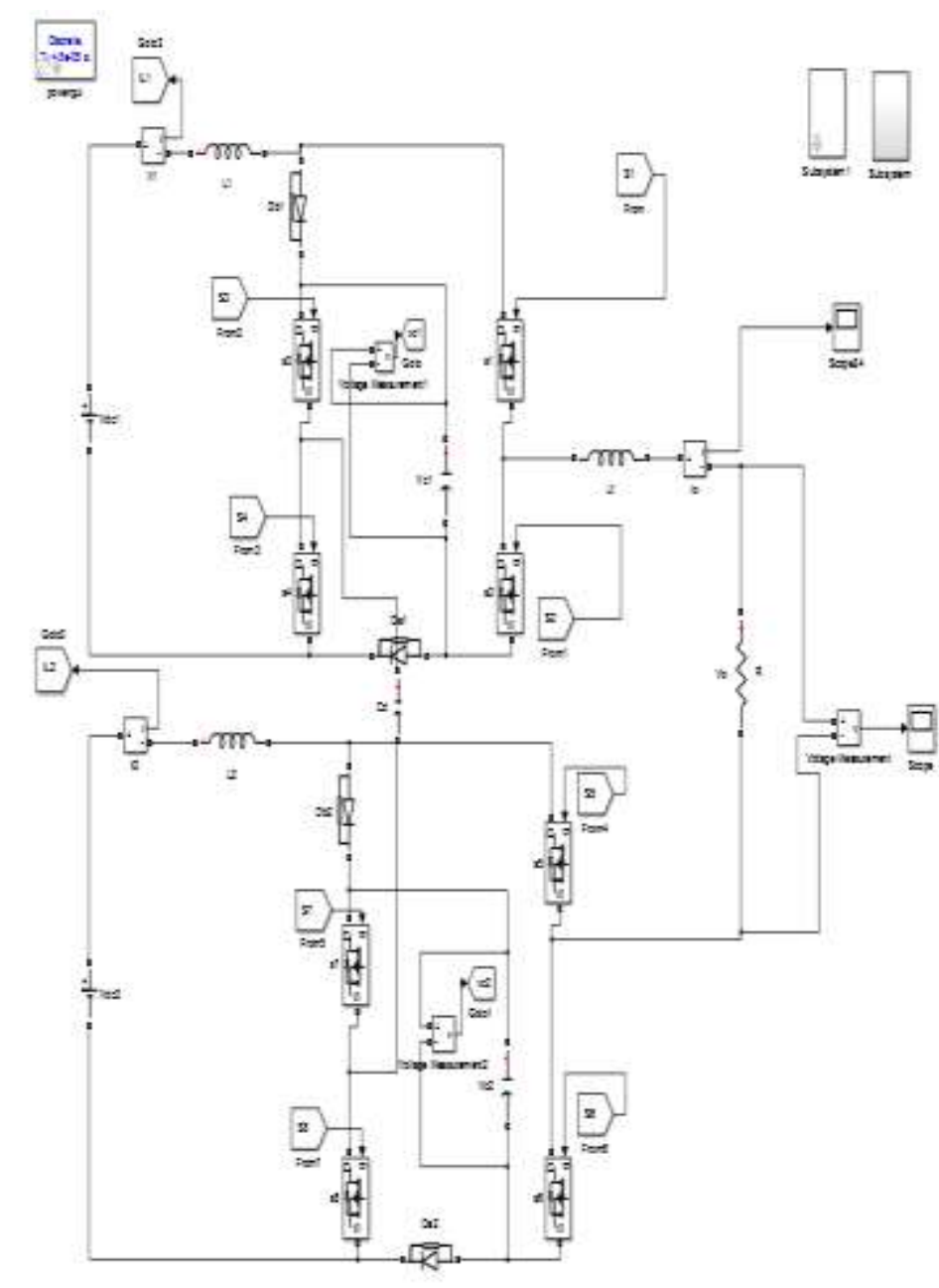

\section{Figure 7.1 Proposed circuit}

\section{Simulation Output}

Simulink Verification and Validation enables systematic verification and validation of models through modeling style checking, requirements traceability and model coverage analysis. Simulink Design Verifier uses formal methods to identify design errors like integer overflow, division by zero and dead logic, and generates test case scenarios for model checking within the Simulink environment. The systematic testing tool TPT offers one way to perform formal test- verification and validation process to stimulate Simulink models but also during the development phase where the developer generates inputs to test the system. By the substitution of the Constant and Signal generator blocks of Simulink the stimulation becomes reproducible 


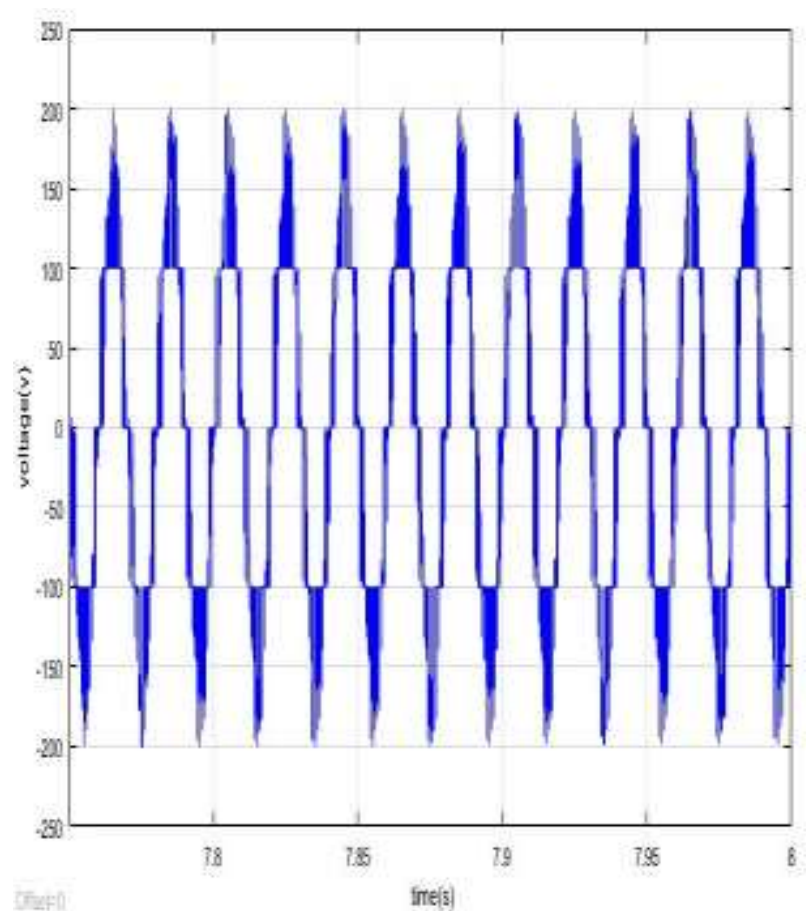

Figure 8.1 The output voltage of the proposed inverter has five levels

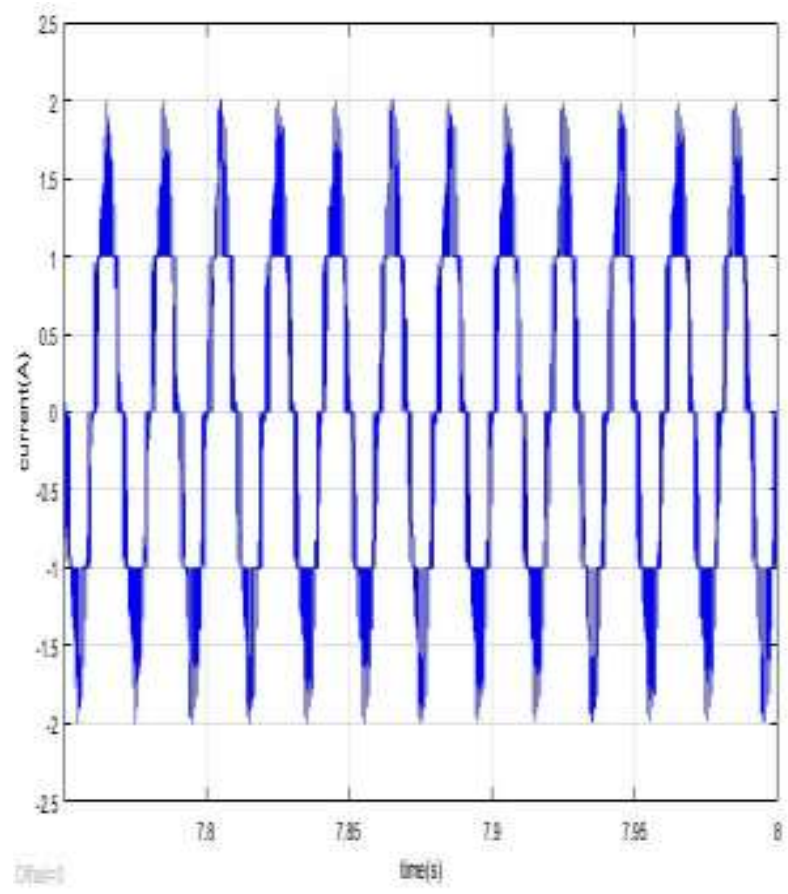

Figure 8.2 Inductor currents

we set $V d c 1=V d c 2=50 \mathrm{~V}$ to confirm the properties of the proposed inverter under balanced DC-source condition. Fig.5.3 shows the simulation results for the proposed QCHB-FLBI when both input voltages are the same. The output voltage of the proposed inverter has five levels; and the load voltage is 110 Vrms.

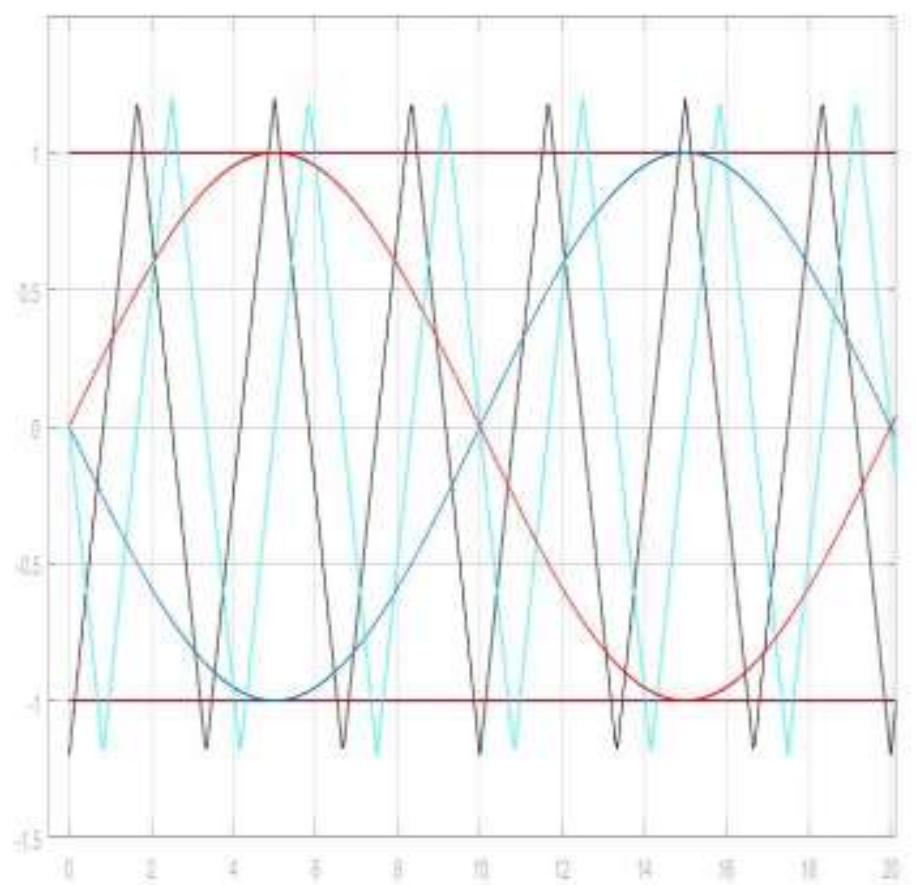

Figure 8.3 PWM scheme for the proposed system

It shows a phase-shifted sinusoidal pulse-width modulation (PS-SPWM) strategy for the proposed QCHB-FLBI. For module 1, two control voltages vcontrol and vcontrol are compared to a highfrequency triangle voltage, Vtril, to produce control signals for the $S 1$ and $S 2$ switches. Two DC voltages, VSH and-VSH, are compared to vtri1 to produce the SOa control signal. Then SOa is added to the control signals of switches $S 1$ and $S 2$ to produce the ST states. Likewise, the Vtril is shifted in $90^{\circ}$ to create another high-frequency triangle voltage, vtri2, vcontrol and -vcontrol are compared to vtri2 to produce control signals for the S3 and S4 switches. $\mathrm{VSH}$ and $-\mathrm{VSH}$ are compared to the Vtri2 to produce a $S O b$ control signal. The $S O b$ is then added to the control signals of switches $S 3$ and $S 4$ to produce the ST states. As a result, the output voltage vab of $\mathrm{H}$ bridge module 1 has three levels.

\section{Conclusion}

Simulation of the single-phase single-stage CHB five-level inverter with boost voltage ability has been verified. The proposed inverter has the following main features as: five-level output voltage, reduction in number of passive components and shoot-through immunity. With the simple PID controller, a constant capacitor voltage can be achieved with an excellent transient performance 
which enhances the rejection of disturbance, including the input voltage and load current variations. Also, circuit analysis and PWM control strategy for the proposed system are shown.

Simulation results are shown to verify the validity of the proposed QCHB-FLBI.

\section{References}

[1] M.ValanRajkumar, P.S.Manoharan, Modeling and Simulation of Three-phase DCMLI using SVPWM for Photovoltaic System, Springer Lecture Notes in Electrical Engineering, under the volume titled "Power Electronics \& Renewable Energy Systems", Volume 326, Chapter No 5, January 2015, Pages 39-45.

[2] M.ValanRajkumar, P.S.Manoharan, Harmonic Reduction of Fuzzy PI Controller based ThreePhase Seven-level DCMLI with SVPWM for Grid Connected Photovoltaic System, Journal International Review on Modeling and Simulations, Volume 6, No 3, June 2013, Pages 684-692.

[3] A.Ravi, P.S.Manoharan, M.ValanRajkumar, "Harmonic Reduction of Three-Phase Multilevel Inverter for Grid connected Photovoltaic System using Closed Loop Switching Control", Journal-IREMOS, Volume 5, No 5, October 2012, Pages 1934-1942. ISSN: 1974-9821 (Print), 1974-982X (Online)

[4] P.Thirumurugan,

P.S.Manoharan, M.ValanRajkumar, "VLSI Based Inverter Switching Control" in the proceedings of International Conference on Mathematical Modeling and Applied Soft Computing MMASC'12 - Coimbatore Institute of Technology on July 2012, Vol-2 (Page):965973.

[5] C.Hemalatha, M.Valan Rajkumar, G.Vidhya Krishnan, "Simulation and Analysis for MPPT Control with Modified firefly algorithm for photovoltaic system", International Journal of Innovative Studies in Sciences and Engineering Technology, Volume 2, No 11, Nov.2016, Pages 48-52.

[6] G.Vidhya Krishnan, M.Valan Rajkumar, C.Hemalatha, "Modeling and Simulation of 13level Cascaded Hybrid Multilevel Inverter with less number of Switches", International Journal of Innovative Studies in Sciences and Engineering Technology, Volume 2, No 11, Nov.2016, Pages 43-47.

[7] M.ValanRajkumar, P.S.Manoharan, FPGA Based Multilevel Cascaded Inverters with
SVPWM Algorithm for Photovoltaic system, Elsevier Journal Solar Energy, Volume 87, Issue 1, January 2013, Pages 229-245.

[8] M.ValanRajkumar, P.S.Manoharan, Space Vector Pulse Width Modulation of Three-Phase DCMLI with Neuro-Fuzzy MPPT for Photovoltaic System, World Journal of Modelling and Simulation, Volume 10, No 3, August 2014, Pages 193-205.

[9] M.Valan Rajkumar, Prakasam, P. and Manoharan, P.S. (2016) Investigational Validation of PV Based DCDMLI Using Simplified SVM Algorithm Utilizing FPGA Tied with Independent Sources. Circuits and Systems, Volume 7, No 11, 3831-3848. http://dx.doi.org/10.4236/cs.2016.711320

[10]P.Thirumurugan, P.S.Manoharan, M.ValanRajkumar, VLSI Based Space Vector Pulse Width Modulation Switching Control in the proceedings of IEEE International Conference on Advanced Communication Control and Computing Technologies ICACCCT 2012 on August 2012, ISBN No. 978-1-4673-2045-0 (Print) (Page):366-370.

[11]M.ValanRajkumar, P.S.Manoharan, "Modeling, Simulation and Harmonic Reduction of ThreePhase Multilevel Cascaded Inverters with SVPWM for Photovoltaic System", Journal International Review on Modeling and Simulations, Volume 6, No. 2, April 2013, Pages 342-350. ISSN: 1974-9821 (Print), 1974982X (Online)

[12]M.Valan Rajkumar, G.Ranjhitha, M.Pradeep, Mohammad Fasil PK, R.Sathishkumar, "Fuzzy based Speed Control of Brushless DC Motor fed Electric Vehicle", International Journal of Innovative Studies in Sciences and Engineering Technology (IJISSET), Volume: 3, Issue: 3, March 2017, Pages 12-17. ISSN: 2455-4863 (Online).

[13]M.Valan Rajkumar, J.Chandramohan, D.Aravind, M.Basker, "Performances Analysis of Power Factor Correction for PWM Control based Bridgeless Cuk Rectifier with Positive Output Voltage", International Journal of Emerging Technologies in Engineering Research (IJETER), Volume: 5, Issue: 4, April 2017, Pages 116-121. ISSN: 2454-6410 (Online).

[14]K.Aswini, K.Nandhini, SR.Nandhini, G.Akalya, B.Rajeshkumar, M.Valan Rajkumar, "Simulation and Analysis of ASCAD Multilevel Inverter with SPWM for Photovoltaic System", International Journal of Innovative Studies in 
Sciences and Engineering Technology (IJISSET), Volume: 3, Issue: 4, April 2017, Pages 1-9. ISSN: 2455-4863 (Online).

[15]M.Valan Rajkumar, M.Mahakumar, M.Manojkumar, M.Hemaraj, E.Kumaravel, "Modelling and Analysis of DC-DC Converter with Various MPPT Algorithms for PV System", International Journal of Innovative Studies in Sciences and Engineering Technology (IJISSET), Volume: 3, Issue: 4, April 2017, Pages 17-22. ISSN: 2455-4863 (Online).

[16]M.Valan Rajkumar, T.Indumathi, "Analysis of Low Power Multi-core Embedded Management for Energy Harvesting", IOSR-Journal of Electrical and Electronics Engineering, Volume 12, Issue 2, Ver. II, March-April 2017, Pages 25-33. ISSN: 2320-3331 (Print) 2278-1676 (Online).

[17]A.Ravi, M.Valan Rajkumar, P.S.Manoharan, "Harmonic Reduction of Three-Phase Elevenlevel DCMLI with Fuzzy MPPT for Grid Connected Photovoltaic System", International Journal of Applied Engineering Research (IJAER), Volume 10, No 2, 2015, Pages 3251-3268. ISSN: 0973-4562 (Print).

[18]M.Valan Rajkumar, J.Karthikeyan, P.S.Manoharan, "Modeling and Simulation of Multiphase DCMLI with SVPWM for Photovoltaic System", International Journal of Applied Engineering Research (IJAER), Special Issue: Volume 9, No 24, 2014, Pages 84778483. ISSN: 0973-4562 (Print).

[19]M.ValanRajkumar, P.S.Manoharan, "Modeling and Simulation of Five-level Five-phase Voltage Source Inverter for Photovoltaic Systems", Journal PrzegladElektrotechniczny, Volume 10, No. 10, October 2013, Pages 237 241. ISSN: 0033-2097 (Print)

[20]M.Valan Rajkumar, P.S.Manoharan, A.Ravi, "Simulation and an Experimental Investigation of SVPWM Technique on a Multilevel Voltage Source Inverter for Photovoltaic Systems", Elsevier International Journal of Electrical Power and Energy Systems, Volume 52, Issue 9, November 2013, Pages 116-131. ISSN: 01420615 (Print), 1879-3517 (Online)

[21]SR.Nandhini, G.Akalya, K.Aswini, K.Nandhini, M.Valan Rajkumar, B.Rajeshkumar, "A New Topology of H-bridge based Multilevel Inverter for PV System with Reduced Switches", International Journal of Emerging Technologies in Engineering Research (IJETER), Volume: 5,
Issue: 4, April 2017, Pages 60-68. ISSN: 24546410 (Online).

[22]M.Valan Rajkumar, M.Mahakumar, M.Manojkumar, M.Hemaraj, E.Kumaravel, “A New DC-DC Converter Topology with Grey Wolf MPPT Algorithm for Photovoltaic System", International Journal of Emerging Technologies in Engineering Research (IJETER), Volume: 5, Issue: 4, April 2017, Pages 54-59. ISSN: 2454-6410 (Online).

[23]S.Rashini, P.S.Manoharan, M.Valan Rajkumar, "Interfacing PV system to the Utility Grid using a Voltage Source Inverter", Journal of Emerging Technologies Electrical Engineering, Special Issue- ICBDM 2013, Volume 1, No 1, March 2013, Pages 124-129. ISSN: 0973-2993 (Print)

[24]S.Sathyaraj, M.Valan Rajkumar, J.Chandramohan, "Modeling and Simulation of Asymmetric Cascaded Multilevel Inverter with Reduced Switches using Multicarrier PWM Control", International Journal of Advanced Research in Electrical, Electronics and Instrumentation Engineering (IJAREEIE), Volume 5, Issue 10, October 2016, Pages 80648071. ISSN: 2320-3765 (Print), 2278-8875 (Online)

[25]G.Ranjhitha, M.Valan Rajkumar, "Implementation of Genetic Algorithm based Maximum Power Point Tracking for Photovoltaic System", International Journal of Innovative Research in Science, Engineering and Technology (IJIRSET), Volume 5, Issue 11, November 2016, Pages 18860-18868. ISSN: 2347-6710 (Print), 2319-8753 (Online)

[26]S.Sathishkumar, M.Valan Rajkumar, R.Yuvaraj, "Modeling and Analysis of Soft-Switched Interleaved Boost Converter for Photovoltaic System", International Journal for Science and Advance Research in Technology (IJSART), Volume 2, Issue 11, November 2016, Pages 4348. ISSN: 2395-1052 (Online)

[27]M.Sundaraperumal, M.Valan Rajkumar, A.Venkatesh, "Modeling and Analysis of Current Source Multilevel Inverter using PI Controllers with Multicarrier PWM Technique", International Journal for Science and Advance Research in Technology (IJSART), Volume 2, Issue 11, November 2016, Pages 275-280. ISSN: 2395-1052 (Online)

[28]R.Yuvaraj, S.Sathishkumar, M.Valan Rajkumar, "Analysis of PV based Soft Switching Boost DC-DC Converter with Zero Current Switching Technique", International Journal of Advanced Research in Management, Architecture, 
Technology and Engineering (IJARMATE), Volume 2, Issue 12, December 2016 Pages 1-5. ISSN: 2454-9762 (Print) 2454-9762 (Online)

[29]M.Valan Rajkumar, M.Mahakumar, M.Manojkumar, M.Hemaraj, E.Kumaravel, "A New MPPT design using Grey Wolf Optimization Techniques with DC-DC Converter for PV System", International Journal for Science and Advance Research in Technology (IJSART), Volume 3, Issue 3, March 2017, Pages 829-835. ISSN: 2395-1052 (Online)

[30]K.Nandhini, SR.Nandhini, G.Akalya, K.Aswini, M.Valan Rajkumar, B.Rajeshkumar, "Implementation of 21-level Asymmetrical Cascaded Multilevel Inverter with Reducing Number of Switches", International Journal for Science and Advance Research in Technology (IJSART), Volume 3, Issue 3, March 2017, Pages 809-818. ISSN: 2395-1052 (Online)

[31]S.Sathishkumar, M.Valan Rajkumar, S.Vinothkumar, M.Maruthamuthu, A.Sounder, A.Kumaresan, "A New Design for DC-DC Converter Topology with MISO for Renewable Energy Resources", International Journal of Emerging Technologies in Engineering Research (IJETER), Volume: 5, Issue: 4, April 2017, Pages 143-149. ISSN: 2454-6410 (Online)

[32]M.Valan Rajkumar, M.Mahakumar, M.Manojkumar, M.Hemaraj, E.Kumaravel, "Implementation of Various MPPT Algorithms with SEPIC Converter for PV System", International Journal of Engineering Research \& Technology-Special Issue 2017, Volume 5, Issue 13, 2017, Pages 589-593. ISSN: 22780181 (Print)

[33]G.Akalya, K.Aswini, K.Nandhini, SR.Nandhini, M.Valan Rajkumar, B.Rajeshkumar, "Modelling and Analysis of Multilevel Inverter for Photovoltaic System", International Journal of Advanced Research Methodology in Engineering \& Technology (IJARMET), Volume 1, Issue 3, May 2017, Pages 36-43. ISSN: 2456-6446 (Online)

[34]Mohammad Fasail PK, M.Pradeep, R.Sathishkumar, G.Ranjhitha, M.Valan Rajkumar, "Speed Control BLDC Motor using Fuzzy Logic and PID Controller fed Electric Vehicle", South Asian Journal of Engineering and Technology, Volume 3, Issue 3, March 2017, Pages 118-131. ISSN: 2454-9614 (Print)

[35]P.Pushparani, M.Valan Rajkumar, R.Suganya, "Simulation and Analysis of SVHM Technique for DCMLI under Transient Conditions with Non-Linear Loads", International Journal of Emerging Technologies in Engineering Research (IJETER), Volume: 5, Issue: 11, November 2017, Pages 90-96. ISSN: 2454-6410 (Online).

[36]R.Suganya, M.Valan Rajkumar, P.Pushparani, "Simulation and Analysis of Boost Converter with MPPT for PV System using Chaos PSO Algorithm", International Journal of Emerging Technologies in Engineering Research (IJETER), Volume: 5, Issue: 11, November 2017, Pages 97-105. ISSN: 2454-6410 (Online).

[37]P.Pushparani, M.Valan Rajkumar, R.Suganya, "Modeling and Analysis of Maximum Power Point Tracking for Photovoltaic System using Fuzzy Logic Controller", International Journal for Science and Advance Research in Technology (IJSART), Volume 3, Issue 11, November 2017, Pages 298-306. ISSN: 23951052 (Online)

[38]R.Suganya, M.Valan Rajkumar, P.Pushparani, "Modeling and Analysis of Sinusoidal PWM Technique for CHB Multilevel Inverter for Photovoltaic System", International Journal for Science and Advance Research in Technology (IJSART), Volume 3, Issue 11, November 2017, Pages 307-315. ISSN: 2395-1052 (Online)

[39]M.Sundaraperumal, M.Valan Rajkumar, D.Aravind, "Simulation and Analysis of APOD Pulse Width Modulation Technique for ZSource Cascaded Multilevel Inverter for Photovoltaic System", International Journal for Science and Advance Research in Technology (IJSART), Volume 3, Issue 11, November 2017, Pages 816-824. ISSN: 2395-1052 (Online)

[40]J. Chavarría, D. Biel, F. Guinjoan, C. Meza, and J. J. Negroni,"Energy-balance control of PV cascaded multilevel grid-connectedinverters under level-shifted and phase-shifted PWMs," IEEE Trans. Ind.Electron., vol. 60, no. 1, pp. 98-111, Jan. 2013.

[41] M. Coppola, F. D. Napoli, P. Guerriero, D. Iannuzzi, S. Daliento, and A.D. Pizzo, "An FPGA-based advanced control strategy of a grid-tied PVCHB inverter," IEEE Trans. Power Electron, vol. 31, no. 1, pp. 806-816,Jan. 2016.

[42] G. Farivar, C. D. Townsend, B. Hredzak, J. Pou, and V. G. Agelidis, "Low-capacitance cascaded H-bridge multilevel StatCom," IEEE Trans.Power Electron, vol. 32, no. 3, pp. 17441754, Mar. 2016.

[43] G. Farivar, B. Hredzak, and V. G. Agelidis, "A DC-side sensorlesscascaded

H-bridge 
multilevel converter-based photovoltaic system,'IEEE Trans. Ind. Electron., vol. 63, no. 7, pp. 4233-4241, July 2016.

[44]F. Khoucha, S. M. Lagoun, K. Marouani, A. Kheloui, and M. E. H.Benbouzid, "Hybrid cascaded H-bridge multilevelinverterinduction-motor-drive direct torque control for automotive applications,"IEEE Trans. Ind. Electron., vol. 57, no. 3, pp. 892899, Mar. 2010.

[45] S. Kouro, M. Malinowski, K. Gopakumar, J. Pou, L. G. Franquelo, B.Wu, J. Rodriguez, M. A. Pérez, and J. I. Leon, "Recent advances andindustrial applications of multilevel converters," IEEE Trans. Ind.Electron., vol. 57, no. 8, pp. 2553- 2580, Aug. 2010.

[46] M. Malinowski, K. Gopakumar, J. Rodriguez, and M. A. Pérez, "A surveyon cascaded multilevel inverters," IEEE Trans. Ind. Electron., vol. 57, no.7, pp. 2197- 2206, July 2010.

[47] J. Napoles, A. J. Watson, J. J. Padilla, J. I. Leon, L. G. Franquelo, P. W.Wheeler, and M. A. Aguirre, "Selective harmonic mitigation techniquefor cascaded H-bridge converters with nonequal DC link voltages," IEEETrans. Ind. Electron., vol. 60, no. 5, pp. 1963-1971, May 2013.

[48] E. Villanueva, P. Correa, J. Rodríguez, and M. Pacas, "Control of asingle-phase cascaded $\mathrm{H}$ bridge multilevel inverter for gridconnectedphotovoltaic systems," IEEE Trans. Ind. Electron., vol. 56, no. 11, pp.4399-4406, Nov. 2009.

[49] S. Vazquez, J. I. Leon, J. M. Carrasco, L. G. Franquelo, E. Galvan, M.Reyes, J. A. Sanchez, and E. Dominguez, "Analysis of the power balancein the cells of a multilevel cascaded $\mathrm{H}$ bridge converter," IEEE Trans.Ind. Electron., vol. 57, no. 7, pp. 2287-2296, Jul. 2010. 